\title{
Structural Organization of Dance Dramaturgy Based on Paintings
}

\author{
Tatiana Portnova ${ }^{1,2}$ \\ ${ }^{1}$ Choreography Art Department, Slavic Culture Institute, Moscow, Russia \\ ${ }^{2}$ Art History Department, A. Kosygin Russian State University, Moscow, Russia
}

Email address:

infotatiana-p@mail.ru

\section{To cite this article:}

Tatiana Portnova. Structural Organization of Dance Dramaturgy Based on Paintings. International Journal of Literature and Arts. Vol. 6, No. 5, 2018, pp. 77-82. doi: 10.11648/j.ijla.20180605.11

Received: August 16, 2018; Accepted: September 14, 2018; Published: October 19, 2018

\begin{abstract}
The article presents the experience of interpretation of matters of interaction between choreographical and dance origins, various forms of conflux of art and dance imagery in the staging design, means of their artistic corellation based of a range of paintings. Constant updating of professional and General culture, skills of practical activity of creative workers throughout life becomes necessity of our era. The author sets a goal to identify methodological paradigms of interdisciplinary research of painting and choreographic arts and on this basis to understand their interaction as a holistic, developing phenomenon of scientific, creative and educational transformations. Consideration of the problems of the article goes according to the following structure; features of the plot in choreography and painting, comparative analysis of paintings and plot drama in dance, aspects of the creative work of the choreographer with the picturesque material. Specific artistic reinterpretation of images of the Russian and Western European painting in choreography is studied, as well as its influence on the creative approach of a Ballet master. Already existing compositional and artistic solutions of dance dramaturgy are listed during the analysis of the staging work of a choreographer, as well as the new possibilities associated with usage of artistic sources. The interdisciplinary nature of the research topic allows to attract a wide range of concepts covering not only formal and methodological, but also substantive aspects of the use of paintings in choreography. In conclusion, attention is drawn to the fact that in a picturesque source you need to be able not only to see the interesting, the main thing, but to be able to explore it, to generalize, a Good plot dance is always deep in its content, drawing images, the integrity of the plan and the brightness of the external form. The experience gained in the work on pictorial images, can give a lot of useful skills, will affect the subsequent plans and preferences. The obtained results allow to deepen, extend and elaborate modern understanding about the concept of "shaped the dramaturgy of the dance". Provisions and guidelines listed in the article are designed not only for students of choreography but also for creative majors of universities, academies of culture and art.
\end{abstract}

Keywords: Choreographic Process, Painting, Ballet Master's Thinking

\section{Introduction}

The changes undergoing not only in the modern choreography but also in other related arts are associated with emergence of new artistic language, elaboration of a new philosophy, and intensive development of new technologies. All the practical work of a future Ballet master should be subject to the development of their skills of creation of a choreographical work, where the main expressive means comprise the dance pattern placed in the substantial form of drama revealing not the image and character of individual actors but also the work as a whole. A Ballet master, being the creator of new works, should have professional knowledge and skills in the field of choreographic composition and performance along with abilities and knowledge of author, playwright and director of the play. The inner gaze of a Ballet master represents a synthesis of sorts, where at first the music is heard, then plastic and color associations appear, then, gradually, the dance appears in greater details, and, finally, the entire play with all its events and imagery. After familiarizing oneself with all necessary materials on the topic under question, namely iconographic, literary, musical and choreographic, 
the Ballet master staging process begins. A work should be based on the principles of drama, so a Ballet master, when staging a dance, has to consider the logic of development of dance patterns, use the principle of contrast and nuance in the structure of the pattern, highlight the upstage, the center stage and the downstage, distribute the pattern over the stage evenly. When creating large ballet forms, the choreographer, first of all, imagines the logical development of characters in actions and deeds determined by the plot. However, along with it, the choreographer contemplates the decorative design, color and form of costumes, necessary props, scenery and stage lighting.

The purpose of the research is the necessity of development of methodology necessary for further study of interaction between various arts in a choreographical work as this interaction becomes one of the defining principles of the structure of the artistic image in the dance culture of the $21 \mathrm{st}$ century. The problem of the research is the generalization of the theory and practice of the modern development of the choreographer's education system and the identification of possible ways to apply the positive experience of the use of pictorial masterpieces in creative practice.

Based on the purpose of the study, it is necessary to justify that the inclusion of the study of plot drama not only in dance, but also in painting will contribute to the development of an integrative system of choreographic thinking, the experience of its implementation can be useful for modern ballet master's world practice.

On this basis, the priorities discussed in the article are formulated:

(1) To find the forms of interaction between visual and choreographic dramaturgy when creating an artistic image;

(2) To define the main principles of plot dramaturgy on illustrative examples of paintings in the author's decisions as an important material for professional training of the choreographer;

(3) To consider aspects of the choreographer's creative work with pictorial material, to characterize its structural components;

(4) To determine the specifics of the further development of the system of integrative education of the choreographer at the present stage. Research of this topic was based on works on aesthetics and philosophy of art by Yuri Lotman [1], Grigory Kreidlin [2], and studies of art historians and choreographers dedicated to the expressive language of ballet theater [3-5]. Other than these, works were studied on various problems of Ballet master's skill mastery and staging work: G. Bogdanov[6], N. Zaikin [7], A. Melekhov [8], works by Jean-Georges Noverre [9], theoretic works by V.I. Uralskaya [10], articles dedicated to the synthesis of arts [11, 12]; works on choreographical dramaturgy of ballet by I. Esaulov, [13] V. Panferov [14], P. Karp [15], [16], Yu. Slonimsky [17]; works on scenography by V. Bazanov [18], V. Berezkin [19] and others.

\section{Methods}

The methodological basis of the research includes principles of comparative historical and systematically structural art history. Methodology of intermedial analysis is based on the study of expressiveness of various arts in the space of their semantic intersection becomes the most productive one for the analysis of choreographic text included in the work with multi-art structure, from the point of view of the interaction of languages of dance and painting. The connection of dance with painting is not limited to the genre of its image in easel painting. In their work, many artists used plots and imagery from famous ballet performances or were inspired by similar situation leading to independent paintings. However, even very talented fixation of a seen image is always derivative. Both choreographical theater and painting are the fully independent art forms, so their interaction can't be largely limited to usage of an existing idea; most of the time it is necessary to identify the points of contact between the two works.

Illustrative examples of painting sources as the design of future work have to be included in the educational structure of disciplines as "Ballet master's Art", "Composition of Dance", "Acting", "Samples of Choreographic Heritage" and "History of Choreography" to form the choreographers' mindset and develop their creative thinking. "As for the choreography, among the other expressive arts it is the most prone to figurativeness, primarily due to the very instrument of dance art: a human body that hardly can be considered a pure decorative element"[20. p.28] Study of examples of interaction of arts through various historical ages not only helps to understand styles and directions of the dance, solidifies the knowledge of ballet terminology, introduces the works of outstanding past and present masters of ballet, but mostly it helps to understand the language of contemporary art as it is in plastic synthesis these artistic principles of the choreographic practice were laid down, further developed in the 20-21 st centuries.

\section{Results}

\subsection{Plot in Choreography and Painting, Its Features}

Plot is considered to be a basis for dance dramaturgy. Plot is an original feature of the fine arts, including painting, but the difference is that for painting its material rather than abstract level can be considered in the broader sense, for instance, in Modernist painting, while it is impossible in the ballet theater in a pure form. Both dance and painting begin at the author's design. It should contain an imaginative and emotional core, which later becomes the basis for both form and content of an artistic work in the process of artistic generalization. The design determines the kind and genre for the future dance and painting, as well as aesthetic nature of form and content, which in turn depend on clear definition of topic and idea of both choreographic and painting work. Topic is related to a range of phenomena of life depicted by an artist; it is directly dependent on content and helps in 
creation of narrative building of performance or painting. In other words, the plot is present in the design already upon definition of topic and genre of a work. However, in the dance plot represents a range of interconnected and consistently developing events. Through these events, the Ballet master demonstrates interrelations and interactions of images. In these (relations and actions) one may find various traits, behaviors and emotions of the characters. On a painting, this is fixed in the most expressive way as a still image. However, both in the painting and in the dance we can observe an event, or an occurring action. It should be noted that the still one-frame plot in the painting is often perceived by the viewer as easier and more understandable to read than the developing story in the dance. Painting has broad scale reflection of reality, the ability to convey its diversity with a high degree of specificity, assuming a lower degree of conventionality, generalization, and ambiguity. While writing a story, choreographers often over-saturate it with events, and suddenly it turns out that there is not enough space for the dance. Even full-length ballets have a limited number of events. The action in a ballet is utterly danceable as it is the main requirement to the choreographical plot. And here, the paintings may be of help to the choreographer, being the samples of succinct dramatic sense embodied in the plots of various genres of paintings.

\subsection{Painting and Plot Dramaturgy in the Dance}

Dramaturgy means plot and image concept of the work, as well as the technique and methods of its structure. Choreographical dramaturgy is a new term introduced in the practice only recently. Before, the dramaturgy of a ballet performance was considered not as a whole but rather by its separate elements. Dramaturgy in music, dramaturgy in decorative design of a performance, dramaturgy in the plot and others: these all were considered separately. Perhaps, it was Yu. Slovisky, who applied the dramaturgy term on the choreographical work in general for the first time. It gave him an opportunity to reveal on what the choreographical action is based, how it is determined, what defines its intensity etc. during the analysis of any given ballet performance. "The term 'dramaturgy' is derived from Ancient Greek 'drama', meaning action. Over time, this term began to be used in a broader sense, in relation to not only drama, but other forms of art as well." [21, p19] "Affinity to such synthesis is demonstrated by drama that gets true depth and strength of aesthetic influence, especially in the theater. Dramatic work is not only performed when on stage, it is translated by the director and actors to the language of theater. In this regard, writers and playwrights, given the specificity of the theatrical embodiment of their creation, develop their own system of the artistic tools needed to create the performance.'[22] Organization and development of narrative dramaturgy in a choreographic performance goes through four stages: the life phenomena being just a possibility of plot, the plot design being a step forward towards realization of life conflict (definition of the main conflict and events; characteristics of images, style, music; selection of a composition; choice of musical material, i.e. creation of a compositional plan and script); writing of dance composition, meaning search of a plastic language, creation of staging and drawings, choice of decoration; implementation of the plot in the performance, meaning the staging of the dance. Among the easel paintings used by us for comparison and analysis in our work, we have only two where are neither the musical solution nor special decorative design, though they have a certain spiritual desire and solution of environment where the drawn characters are immersed.

The main principle of plot dramaturgy requires that all events be associated with the main conflict. The conflict is expressed through disagreement, clash of opposing views and aspiration on which the struggle of actors is based in the artistic work. The main seed of conflict is the absence or violation of harmony of personal and public, between the needs and obstacles lying before them. Jean-Georges Noverre said: "Human passions have a certain degree of ardor that can't be expressed by words, or, rather, words aren't enough for them. That's when the triumph of action dance comes into play. One step, one gesture, one movement can express something that can't be expressed by any other means. The stronger the feeling that is to be expressed, the harder it is to put it into words"[23, p.45] Even in plotless ballets where there are no events, visible conflicts, confrontation of the characters, performers come on stage, actors that are perceived by viewers. All action line of their behavior, development and revelation of characters related in some way or another, is composed and recreated by a choreographer. It is always a plot to him, constructed based on principles of dramaturgy with its characters living and acting according to the rules of stage logic and the human psyche.

Studying the paintings, it is possible to find forms of interaction between visual and choreographic dramaturgy in the creation of an artistic image. Any painting is also constructed on the principles of dramaturgy governing the imagery. While any stage character should have its own exposition, introduction, steps before the climax (development of action), the climax and the denouement, we can observe the same in paintings, but in separately existing milestone points. For instance, ballet critic L. A. Linkova specifies four most general ones: contrast of adjacent episodes; emotional highs and lows; meaningful rhythmical organization; and a tendency to the climax. [24] This can be said not only for dramatic direction, but also for the visual one. The painting can demonstrate the moment preceding the event, the moment of occurring action and the moment following the completed event. For instance, it seems that nothing goes on at the major painting The Appearance of Christ Before the People by Alexander Ivanov (1837-1857, State Tretyakov Gallery); all the people gathered at the Jordan river are only in premonition for the Christ to come, with gazes of many of them, including John the Baptist, are directed to the small figure of Christ visible over the horizon. 
This episode, being depicted on the painting, can be compared with exposition or introduction of a dramatic performance, backstory of beginning of the intrigue. The next step in the dramaturgical structure of a choreographic work is the development of action, meaning sudden changes in the unfolding conflict, complication of the circumstances in which the characters act. In this regard, Vasily Surikov's painting Menshikov in Beryozovo (1883, State Tretyakov Gallery) is quite illustrative. Alexander Menshikov was sent into exile together with his family. He is depicted in a small log hut with a low ceiling despite this man being accustomed to entirely different surroundings. Conflicts and features established in the introduction are being unfolded and more complex here. The Last Supper, by Nikolai Ge (1863, State Russian Museum), depicts the most dramatic moment in the Bible: Communion of the Apostles. It is the moment the famous words "One of you shall betray me" were said, with Judas depicted at the foreground of the painting. He is turned to the audience and leaving, and everything was sent into confusion in this room, where the peaceful supper was held. From the point of view of choreographical dramaturgy, it is the development of action: here we see not just development, but rather the climax, the highest point of intrigue, the highest intensity of passion, the pinnacle of the relationship between the characters (actors, characters). An artist has to design and develop his images in the way that it leads to the artistic truth of the depicted action. Finally, a striking example of the denouement, completing the intrigue, is a well-known picture of Ilya Repin "Ivan the Terrible and His Son Ivan" (1885, State Tretyakov gallery). The painting captures the reaction of Tsar Ivan the Terrible to the murder of his son by his own hands, i.e. the moment after the action was done, leading to the conclusion. The analyzed stages of dramaturgical structure in choreography are inter-related. Each following element seamlessly follows from the previous one, completing and unwinding the image and content picture of the entire choreographic work. Not by chance they are often called dramaturgic laws. For the choreographic character having the full and vivid expression on stage, the Ballet master should present clear and specific objectives before himself and the dancer, coming from the action, the plot, the idea of work, and the through line image. The action in the painting or, more precisely, its parabola is more perceptible. In each specific work, the development of intrigue is determined by the situation and shown circumstances designed and implemented by the artist. Paintings, as if broken down, compositionally structured, may help in building the structure of a work in the Ballet master's creative process, in the skill of selection of all necessary dramaturgical stages by only the means of other art, the means of choreography.

\subsection{Aspects of the Choreographer's Creative Work with Paintings}

History of choreography has numerous examples of the painting holding a special place in the work of Ballet masters and dancers. From this point of view, the work of each and every of them can be considered separately. In their dramaturgy it comes in many different forms. On the one hand, they use direct references to masterpieces of the famous artists that help both the audience and the director to imagine a stage situation. On the other hand, the relationship with painting can be traced to usage of different colors and color combinations on the stage, acquiring symbolic meaning in the particular context.

Turning to the narrative dramaturgy, we can identify three possible means of interaction between dance and painting.

Firstly, it can be the full-fledged adaptation of the painting material by the Ballet master, for instance, the Liberty Leading the People by Eugène Delacroix (1830, Louvre, Paris) becomes a symbol of sorts in the ballets "Flame of Paris" and "Gavroche" by B. Bitov. The image of the easel painting with characters depicted on it is not a background of the stage, but rather as actor; during the performance it sometimes acquires the recognizable plastic image seen by us on the source material. It should be emphasized that in this case, a bold departure is needed from its external action, as well as full remake of the plot, i.e., the creation of a new work, completely different from the original. Even the most picturesque scenario is likely to bear no fruit if it doesn't produce choreographical images in the Ballet master's imagination. Starting from the painting plot and based on the musical material, the choreographer has to write a graphic dance text for the audience to understand the meaning of the dance.

Secondly, another option presumes the creation of a painting on historical and cultural basis, including the painting one, when a painting is not directly related to choreographic story, but rather recreates the image of one or more of the characters of the work. Isadora Duncan, famous American dancer, recalls: "This time my imagination was captivated by Sandro Botticelli. I spent a few days in front of his famous painting Primavera. Inspired by it, I created a dance, trying to embody in it the necessary motions suggested by the painting. I thought: "While dancing this painting, I'll send everyone a message of love, of spring, of birth of life..." Such were my thoughts in front of Botticelli's Primavera, later to be attempted by me to turn into a dance called the Future Dance." [25] Character means a character in the work not influencing the action by itself, but helping to highlight and enlarge the actions on the stage, make the episode entertaining. Development of the image means its revelation through the character. External features of the performer play major part in the embodiment of an image on the stage as everything there is expressed by movements of human body and facial expressions. In the dramatic work, a character played by actor always has some feature; nature of the person becomes the basis for its work.

Thirdly, the ballet theatre borrowing and transforming techniques from a variety of paintings or styles, including those not directly related to dance. The design of many works is based on paintings: mythological, historical and fairy-tale plots, landscapes, still life, animalistic images. Conditions and actions are needed for the character to shine. 
Choreography embodies not only the specific images, but also generic topics and emotional conditions, showing them in an enlarged form, as if through a magnifying glass.

The latest performances in Moscow and Saint Petersburg within the Festival of modern art education are the representative examples of the unity of dance and painting.

"Theater of Painting" by L. Telyatnikova (Moscow) shown the play "And so the painting appears...", demonstrating with original choreography and voiced the plots of paintings by famous artists. "The source for miniatures was the author's hand of each of the artists, historical context of their work and hidden subtexts. Costumes and dance movements of each act are different, so emphasizing the identity of each author" [26] The repertoire of the theater includes several programs for paintings of French Impressionists and Russian modernism as well as ancient Greek vases and Egyptian frescoes. The major part of the repertoire comprises the Russian Seasons cycle based on works by the World of Art artists.

In Saint Petersburg, the evening of modern ballet "Dance and Painting" was held, choreography by L. Ivanova. A unique performance was offered to the audience, representing the story about painting expressed by the language of dance. "Behind the surface of canvas, a deep philosophical meaning is always hidden, and in the play it will be told by the language of movements" [27] The program was dedicated to six cycles of works by the Saint Petersburg artist I. Ivanov: "Two Figures", "Doll", "Flowers", "Crumpled paper", "Sails", and "Pierrot". The audience was engulfed in an endless stream of moves, sharp angles and smooth curves, fine lines and broad strokes - all that can be found in the paintings by this artist. "Dance, being directed by Larisa Inanova, becomes an instrument through which the audience is filled by all the ideas, thoughts and emotions, reaching the very soul, animating the sounds and saturating the air with them" [27] Apart from the dance itself, the audience learns the mysteries of paintings thanks to the costumes made by I. Semenova, artist of the "Interball" theater. The final chord of everything that's happening was the video installation of the works on the background, engulfing the audience in the unusual world of unity of dance and painting.

\section{Discussion}

Thus, the stage choreography is always narrative. Every dance has the beginning with its development commonly based on the dramaturgy laws. Stable patterns are inherent to all the kinds of development, serving as the basis for a choreographical work. These patterns and rules of structure were developed and fixed by the selection of a thousand-year practice of artists communicating with the audience. As of now, the topics of the plots are varied, spanning from the simple everyday situations to deep philosophical reflection. It should be noted that the creation of a choreographic image is an individual process. Observation, emotion, intuition and imagination are the most important components of the choreographer's talent. Work with the painting material is not simple, but it is effective. It is necessary to be able to not only see the interesting and the main things in a painting source, but also being able to study and generalize it. A good narrative dance is always deep in its content, imagery, integrity of design and external brightness. The experience gained in the work on painting images can provide a lot of useful skills, and it will be reflected in subsequent plans and preferences. It expands the horizons of ideas, teaches thinking big.

\section{Conclusion}

Note that the effect of different types of art on the ballet theatre in various periods was highly diverse, multifaceted and intense. Various artistic techniques, new means of expression, topics and images of the painting: all of this was actively assimilated by choreography. Many artistic means and discoveries of the 20th century continue to be relevant even today; choreography of a new century is being created based on them. The further development of ballet theatre in collaboration with other plastic arts, particularly the painting reviewed by us, in many ways foreshadows the emergence of talented choreographers that are capable to embody in their work all the richness and variety of new artistic forms and means of expression inherent to the contemporary art.

\section{References}

[1] Lotman, Yu. M. "Stage and painting as the coding means of cultural behavior of the early nineteenth century" / Yu. M. Lotman about art. Saint Petersburg: Iskusstvo, 1998 - P. 636645 .

[2] Kreidlin, G. E. "Nonverbal semiotics: Body language and natural language". M: Novoe literaturnoe obozrenie, 2002. - 581 p.

[3] Astakhova O. A. "To the matter on the topic of choreography in classical ballet". / Music and choreography of modern ballet.- M. - 1982., Vol. 4. P. 72-86.

[4] Dubnik, I. O. "Specifics of the imagery in choreographic arts: Dissertation". - Moscow: $1984-191$ p.

[5] Makedonskaya. I. V. "Reflections on the dramatic art in classical ballet". - Moscow: MGAKh, 2002. -99 p.

[6] Bogdanov, G. F. "Composition and choreography" - M: Moscow state University of culture -2007-216.

[7] Zaikin. N. I. "The choreographer's skill” - Orel: OGIIK, 2007 -248 p.

[8] Melekhov, A. V. "The Ballet master's art. Composition and production of dance. A work book". Ural State Pedagogical University — Ekaterinburg:2015. - 128 p.

[9] Jean-Georges Noverre "Letters about the dance". - Moscow Leningrad, 1965. $-376 \mathrm{p}$.

[10] Uralskaya, V. I. "Expressive means of contemporary choreographic art". / Matters of education of a choreographer in a theatrical university. Collected articles. Moscow: GITIS, 1980. - P. 31 
[11] Waks, P. "Playwright of painting". An article about Repin. http://www.proza.ru/2017/05/03/1815.

[12] Fedorenko. O. J. "Painting as a way of expressing artistic conventions in the dramaturgy of Tennessee Williams"./ Modern Philology: materials of the 5th international scientific conference (Samara, March 2017). - Samara: ASGARD, 2017. - P. 26-29

[13] Esaulov, Igor Grigorevich. "Choreodramaturgy". - Izhevsk: Udmurt University, 2000. - 318p.

[14] Panferov, V. I. "Fundamentals of dance composition". Chelyabinsk: ChGAKI: 2003. -255 p.

[15] Karp, P. M. "Ballet and drama". - Leningrad: Iskusstvo, 1980. $-246 \mathrm{p}$.

[16] Karp, P. M. "The time and place of the ballet". / The Mariinsky theatre. -2010. - Saint Petersburg. - Nos. 3-4. - P. 18-19.

[17] Slonimsky I. Yu. "Dramaturgy of ballet theatre of the XIXth century". Moscow: Iskusstvo, 1997. - 343 p.

[18] Bazanov, V. V. "The stage of the XX century: A work book". Leningrad: Iskusstvo, 1990-238 p

[19] Berezkin, V. I. "The artist's theatre. The origins and beginning". - Moscow: Librokom, 2012 -296 p.
[20] Ryazanova, Yu. Yu. "New means of expression in the art of ballet to the problems of tradition and innovation". Abstract. Moscow, 2016. $-32 \mathrm{p}$.

[21] Slonimsky I. Yu. "Dramaturgy of ballet theatre of the XIXth century". Moscow: Iskusstvo, 1997. - 343 p.

[22] Fedorenko. O. J. "Painting as a way of expressing artistic conventions in the dramaturgy of Tennessee Williams"./ Modern Philology: materials of the 5th international scientific conference (Samara, March 2017). - Samara: ASGARD, 2017. - P. 26-29.

[23] Jean-Georges Noverre "Letters about the dance". - Moscow Leningrad, 1965. $-376 \mathrm{p}$.

[24] Linkova. L. A. "On drama ballet / Music and choreography of modern ballet”. - Leningrad: Muzyka, 1979. — Vol. 3. - P. $54-71$.

[25] Duncan I. "The Future Dance. My life. Memoirs of L. Schneider". - Kiev: Muza, 1994. - 349 p.

[26] https://www.m24.ru/articles/festivali/13052015/73161?utm_so urce $=$ CopyBuf.

[27] https://spb.kassir.ru/teatr/tanets-i-jivopis. 